\title{
Association of obesity and long-term mortality in patients with acute myocardial infarction with and without diabetes mellitus: results from the MONICA/KORA myocardial infarction registry
}

Miriam Giovanna Colombo ${ }^{1,2^{*}}$, Christa Meisinger ${ }^{1,2}$, Ute Amann $^{1,2}$, Margit Heier ${ }^{1,2}$, Wolfgang von Scheidt ${ }^{3}$, Bernhard Kuch ${ }^{3,4}$, Annette Peters ${ }^{2}$ and Inge Kirchberger ${ }^{1,2}$

\begin{abstract}
Background: Paradoxically, beneficial effects of overweight and obesity on survival have been found in patients after cardiovascular events such as acute myocardial infarction (AMI). This obesity paradox has not been analyzed in AMl patients with diabetes even though their cardiovascular morbidity and mortality is increased compared to their counterparts without diabetes. Therefore, the objective of this long-term study was to analyze the association between body mass index (BMI) and all-cause mortality in AMl patients with and without diabetes mellitus.

Methods: Included in the study were 1190 patients with and 2864 patients without diabetes, aged 28-74 years, recruited from a German population-based AMI registry. Patients were consecutively hospitalized between 1 January 2000 and 31 December 2008 with a first ever AMI and followed up until December 2011. Data collection comprised standardized interviews and chart reviews. To assess the association between BMI and long-term mortality from all causes, Cox proportional hazards models were calculated adjusted for risk factors, co-morbidities, clinical characteristics, in-hospital complications as well as medical and drug treatment.

Results: AMI patients of normal weight (BMI $18.5-24.9 \mathrm{~kg} / \mathrm{m}^{2}$ ) had the highest long-term mortality rate both in patients with and without diabetes with 50 deaths per 1000 person years and 26 deaths per 1000 person years, respectively. After adjusting for a selection of covariates, a significant, protective effect of overweight and obesity on all-cause mortality was found in AMl patients without diabetes (overweight: hazard ratio (HR) $0.73,95 \%$ confidence interval (Cl) 0.58-0.93; $p=0.009$; obesity: HR 0.64, 95\% Cl 0.47-0.87; $p=0.004$ ). In contrast, an obesity paradox was not found in AMl patients with diabetes. However, stratified analyses showed survival benefits in overweight AMl patients with diabetes who had been prescribed statins prior to AMI (HR 0.51,95\% Cl 0.29-0.89, $\mathrm{p}=0.018$ ) or four evidence-based medications at hospital-discharge (HR 0.52, 95\% Cl 0.34-0.80, $\mathrm{p}=0.003$ ).
\end{abstract}

Conclusion: In contrast to AMI patients without diabetes, AMI patients with diabetes do not experience a survival benefit from an elevated BMI. To investigate the underlying reasons for these findings, further studies stratifying their samples by diabetes status are needed.

Keywords: Acute myocardial infarction, Overweight, Obesity, Body mass index, Diabetes mellitus, Long-term mortality, Obesity paradox

\footnotetext{
* Correspondence: Miriam.Colombo@helmholtz-muenchen.de

${ }^{1}$ Central Hospital of Augsburg, MONICA/KORA Myocardial Infarction Registry, Stenglinstr. 2, 86156 Augsburg, Germany

${ }^{2}$ Helmholtz Zentrum München, German Research Center for Environmental Health $(\mathrm{GmbH})$, Institute of Epidemiology II, Ingolstädter Landstr. 1, 85764

Neuherberg, Germany

Full list of author information is available at the end of the article
}

\section{Biomed Central}

(c) 2015 Colombo et al.; licensee BioMed Central. This is an Open Access article distributed under the terms of the Creative Commons Attribution License (http://creativecommons.org/licenses/by/4.0), which permits unrestricted use, distribution, and reproduction in any medium, provided the original work is properly credited. The Creative Commons Public Domain Dedication waiver (http://creativecommons.org/publicdomain/zero/1.0/) applies to the data made available in this article, unless otherwise stated. 


\section{Background}

An elevated body mass index (BMI) is an independent risk factor for increased all-cause mortality in the general population [1]. Furthermore, overweight and obese people are more likely to be affected by cardiovascular events than people of normal weight [2]. However, a controversial survival benefit after cardiovascular events, such as acute myocardial infarction (AMI), has been detected in overweight and obese people [3-8].

Besides excess body weight, diabetes mellitus is a strong risk factor for cardiovascular morbidity and mortality $[9,10]$. People with diabetes have a significantly increased cardiovascular mortality risk that is even further elevated after an established cardiovascular event [10-12], such as AMI [13]. Furthermore, they show worse short- and longterm outcomes after cardiovascular interventions [14,15] in comparison with people without diabetes. However, only a few studies have examined the association between BMI and long-term mortality after a cardiovascular event separately for patients with and without diabetes and showed inconsistent results [16-18].

Thus, the nature of the obesity paradox in AMI patients cannot be explained thoroughly so far. Additionally, longterm studies controlling for important comorbidities, treatment prior and post AMI as well as in-hospital complications have not been conducted on this topic yet.

Therefore, the objective of this long-term observational study was to analyze the association between BMI and allcause mortality in patients with and without diabetes using data from an established German myocardial infarction registry and adjusting for a number of relevant risk factors, co-morbidities, clinical characteristics and inhospital complications as well as treatment measures.

\section{Methods}

As part of the World Health Organization (WHO) project MONICA (Monitoring Trends and Determinants in Cardiovascular disease) the population-based Augsburg Myocardial Infarction (MI) Registry was established in 1984. MONICA was terminated in 1995 and the registry became part of the KORA (Cooperative Health Research in the Region of Augsburg) framework. Since the registry commenced, all cases of coronary death and non-fatal AMI cases of the 25- to 74-year old study population in the city of Augsburg and the two adjacent counties (about 600,000 inhabitants) have been continuously registered. Patients admitted to one of the eight hospitals in the study area and two adjacent counties are included. Methods of case identification, diagnostic classification of events as well as data quality control have been described in detail elsewhere $[19,20]$. Data collection and follow-up questionnaires of the MONICA/KORA MI registry have been approved by the ethics committee of the Bavarian Medical Association (Bayerische Landesärztekammer) and have been performed in accordance with the Declaration of Helsinki. All study participants gave written informed consent.

\section{Study population}

This study includes all patients consecutively registered between 1 January 2000 and 31 December 2008, who reached the hospital alive and whose survival time exceeded 28 days after AMI. Patients were followed up until December 2011. The data set comprised 5057 patients with a non-fatal first ever AMI aged 28-74 years. Patients with missing data on BMI, diabetes and smoking $(n=649)$ were excluded as well as patients with incomplete data on any of the relevant covariates $(n=329)$. Furthermore, patients who were underweight $\left(\mathrm{BMI}<18.5 \mathrm{~kg} / \mathrm{m}^{2}\right.$ ) were not included. The final data set comprised 4054 patients.

Patients excluded from the study sample had a significantly higher crude hazard ratio (HR) for long-term mortality (HR 2.47, 95\% confidence interval (CI) 2.172.82; $\mathrm{p}<0.001)$ compared with included patients.

\section{Data collection}

Trained study nurses interviewed the study participants during their hospital stay using a standardized questionnaire. The interviews covered demographic information, risk factors, medications prescribed prior to AMI, and Comorbidities. Information on AMI characteristics, medical and drug treatment and in-hospital complications were determined by chart review.

BMI was selected as the index to measure and classify normal weight, overweight and obesity. It was determined by assessment of weight and height during hospital stay and calculated for each patient by dividing the weight (in kilograms) by the square of the height (in meters). According to the WHO, patients are classified as normal weight if their BMI lies between 18.5 and $24.9 \mathrm{~kg} / \mathrm{m}^{2}$. Overweight patients have a BMI between 25.0 and $29.9 \mathrm{~kg} / \mathrm{m}^{2}$ and the BMI of obese patients is $30.0 \mathrm{~kg} / \mathrm{m}^{2}$ or higher [21].

Whether patients were suffering from diabetes mellitus was determined by asking the patients if they had been previously diagnosed with the disease (yes/no). In addition, the information provided by the patients was confirmed by chart review.

Since 2004 a combination of the following four evidencebased medications (EBMs) is considered the standard of care after AMI: anti-platelet agents, beta-blockers, angiotensin-converting enzyme inhibitors (ACEIs) or angiotensin-receptor blockers (ARBs) respectively, as well as statins [22]. Since in-hospital complications, such as cardiogenic shock, occurred infrequently, a variable summarizing the data on all complications available in the data set (cardiac arrest, pulmonary edema, bradycardia, re-infarction, ventricular tachycardia, ventricular fibrillation, cardiogenic shock) was created (yes/no). 
To determine all-cause mortality as the outcome of this study, the vital status of the patients in the study population was monitored through the population registries in- and outside the study region until 31 December 2011. The median follow-up time was 6.0 years (IQR 4.1 years).

\section{Data analysis}

Categorical variables were expressed as percentages and continuous variables as mean values with standard deviation (SD). Patients were divided into two groups: patients with and without diabetes. Within the two groups, potential covariates were cross-tabulated with BMI (normal weight, overweight and obesity) as the primary independent variable. Differences in frequencies were tested using $\mathrm{Chi}^{2}$ or Fisher's exact test. To evaluate age differences among the three BMI groups, a one-way ANOVA (analysis of variance) was performed. KaplanMeier plots were generated along with bivariate log-rank tests against survival to test for statistical significance.

Cox proportional hazards models were used to examine the association between BMI group and long-term mortality within the two strata (patients with and without diabetes). The proportional hazards assumption (parallel lines of $\log (-\log ($ event $))$ versus $\log$ of event times) proved to be valid for the majority of the variables except for BMI, age, marital status, education, smoking status, year of infarction, AMI type and ACEIs/ARBs (medication prior infarction). Included as time-dependent covariates, further analyses were made with these variables not complying with the proportional hazards assumption. The results were either not significant and the interaction terms were therefore not included in the analyses or the interaction terms did not make it into the final regression models because they were dropped during the process of backwards selection.

Four Cox proportional hazards regression models were calculated stratified by diabetes (yes/no). First, a crude model was calculated to examine the association between BMI and mortality. Second, a minimal model additionally including the covariates sex and age was calculated. Finally, two parsimonious models, one for patients with diabetes and one for patients without diabetes, were created using backward selection. Variables that made a statistically significant $(\mathrm{p}<0.05)$ contribution were included in the models. The variables sex and age were forced to stay in the models. In order to control for potential cohort effects, we tested whether the year of AMI had an influence on the association between BMI and mortality in both groups, but no effects were found.

Multicollinearity among the independent variables was examined by assessing variance inflation factors (VIF) in the full model prior to backward selection [23].
Interaction effects of sex and age and of BMI group with AMI treatment-related variables were calculated. Significant interaction effects between BMI group and statin treatment prior to AMI as well as prescription of all four EBMs at discharge were found in patients with diabetes. Thus, parsimonious models were separately calculated stratified by statins as medications prior AMI (yes/no) and by receiving all four EBMs at discharge (yes/no).

Finally, parsimonious models were calculated for followup periods of one to twelve years in one-year intervals. All data analyses were performed using SAS software, version 9.2 (SAS Institute).

\section{Results}

The study sample consisted of 1190 patients with diabetes (29.4\% of the total population) and 2864 patients without diabetes (see Table 1). Both among patients with and without diabetes overweight individuals accounted for the highest percentages with $43.4 \%(n=516)$ and $49.3 \%(n=1411)$, respectively. In both groups normal weight patients were more likely to have a LVEF $<30 \%$, to receive coronary artery bypass surgery and less likely to receive PCI or any reperfusion treatment compared with overweight or obese individuals. More patients who were overweight or obese than patients who were of normal weight have received prior treatment with ACEIs/ARBs or beta-blockers (only among patients with diabetes). Discharge medication was more common in overweight and obese patients in terms of ACEIs/ARBs, all four EBMs, antiplatelet agents (only in patients with diabetes) and beta-blockers (only in patients without diabetes). Further sample characteristics are presented in Table 1 and Additional file 1.

Overall, patients with diabetes had a higher long-term mortality rate (40 deaths per 1000 person years; $n=273$ ) than patients without diabetes (21 deaths per 1000 person years; $\mathrm{n}=366)$. With 50 deaths per 1000 person years $(\mathrm{n}=66)$ and 26 deaths per 1000 person years $(n=135)$ normal weight individuals had the highest long-term mortality rate both among patients with and without diabetes, respectively (see Table 1). Furthermore, Kaplan-Meier survival curves demonstrated significant differences in survival between BMI groups in patients without diabetes $(\mathrm{p}=0.003)$; in patients with diabetes, however, a difference could not be proven ( $\mathrm{p}=0.177$ ) (see Figure 1).

The unadjusted analyses showed significant protective effects of overweight and obesity in comparison to normal weight on long-term mortality among patients without diabetes; however the same effects could not be proven in patients with diabetes (see Table 2). For overweight and obese patients without diabetes the HRs showed minimal variation even after adjusting for other covariates in the parsimonious models (see Table 2). Overweight patients without diabetes had a statistically significant 0.73 -fold risk of dying (95\% CI 0.58-0.93; $\mathrm{p}=0.009$ ) and obese patients without 
Table 1 Characteristics of patients with and without diabetes sub-divided into BMI groups ( $N=4054)$

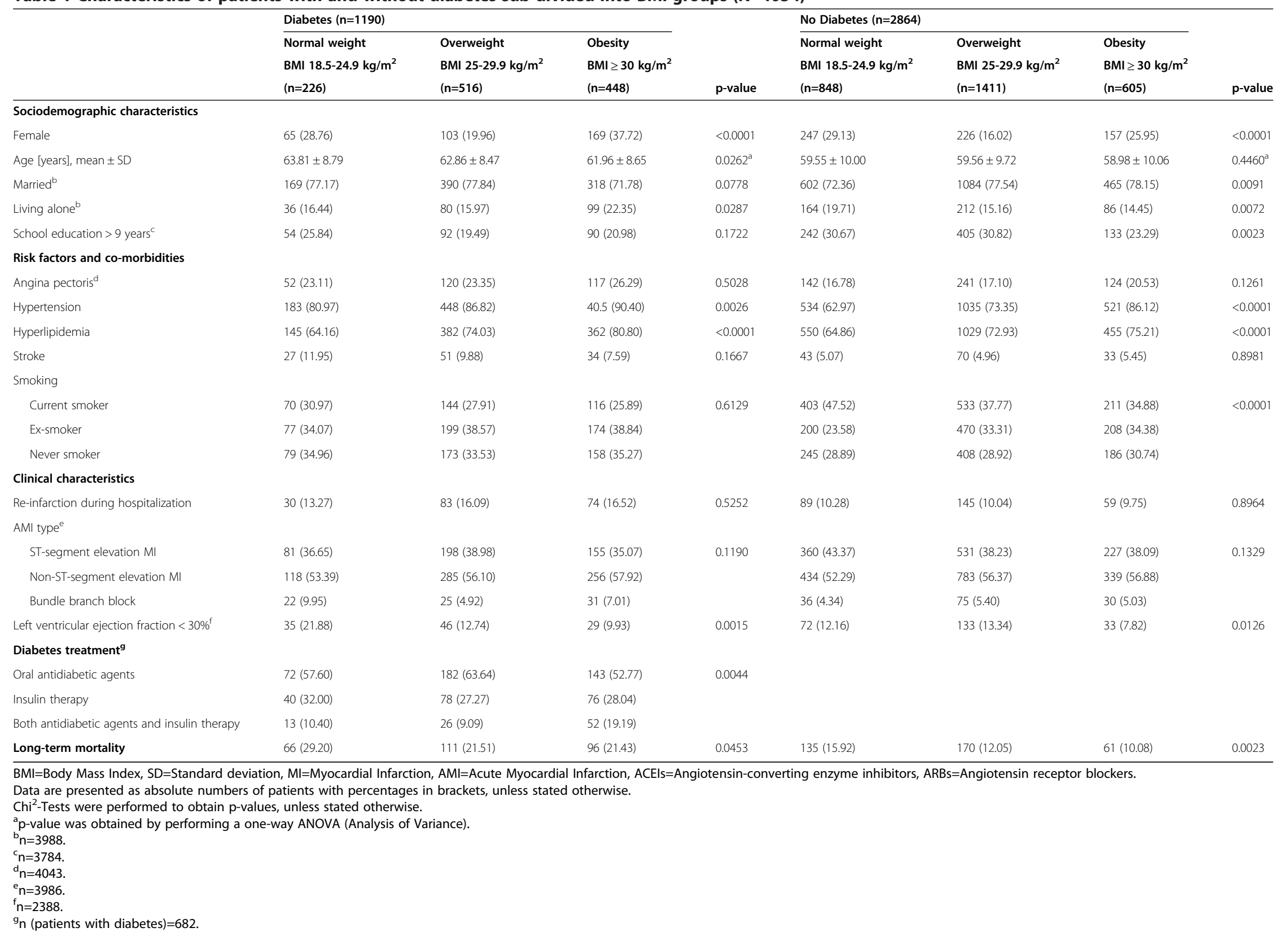




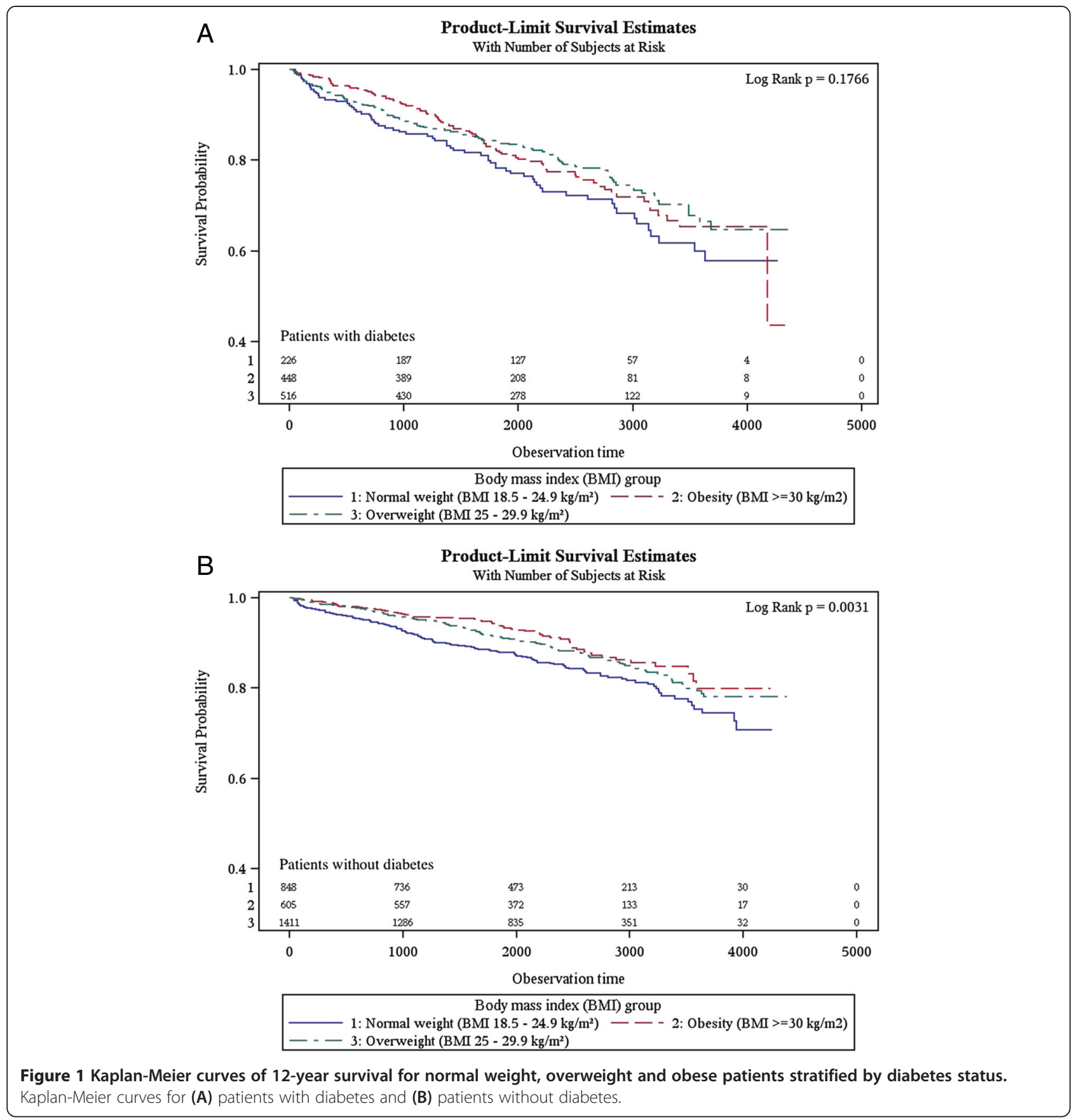

diabetes had an even lower HR of 0.64 (95\% CI 0.47-0.87; $\mathrm{p}=0.004$ ) compared with normal weight patients. In both BMI groups the HRs for patients with diabetes attenuated when covariates were added into the models, however, they remained non-significant.

In the parsimonious models VIF were below 2.5 indicating no relevant multicollinearity among the covariates.

Furthermore, parsimonious models for different observation times (one to twelve years, in 1-year intervals) were calculated comparing HRs of overweight and obese patients with and without diabetes (see Additional files 2 and 3). It could be shown that in AMI patients without diabetes there is a significant protective effect of overweight and obesity on all-cause mortality, which attenuated with increasing observation time while remaining statistically significant. However, in AMI with diabetes being overweight or obese did not result in a survival benefit.

Additionally, parsimonious models were calculated independently stratified by intake of statins prior AMI and number of medications taken at discharge (see Table 3). The stratified analyses resulted in statistically significant HRs of 0.51 (95\% CI 0.29-0.89; p=0.0180) and 0.52 (95\% CI 
Table 2 Hazard ratios for mortality associated with elevated body mass index in patients with and without diabetes

\begin{tabular}{|c|c|c|c|c|c|}
\hline & & \multicolumn{2}{|c|}{ No diabetes $(n=2864)$} & \multicolumn{2}{|c|}{ Diabetes $(n=1190)$} \\
\hline & & $\mathrm{HR}[95 \% \mathrm{Cl}]$ & p-value & $\mathrm{HR}[95 \% \mathrm{Cl}]$ & p-value \\
\hline \multirow[t]{3}{*}{ Unadjusted model } & Normal weight & 1.0 & & 1.0 & \\
\hline & Overweight & $0.74[0.59-0.93]$ & 0.0097 & $0.76[0.56-1.02]$ & 0.0707 \\
\hline & Obesity & $0.62[0.46-0.85]$ & 0.0023 & 0.79 [0.58-1.09] & 0.1495 \\
\hline \multirow[t]{3}{*}{ Minimal model ${ }^{\mathrm{a}}$} & Normal weight & 1.0 & & 1.0 & \\
\hline & Overweight & $0.72[0.57-0.90]$ & 0.0040 & 0.80 [0.59-1.08] & 0.1467 \\
\hline & Obesity & $0.64[0.47-0.86]$ & 0.0036 & $0.91[0.77-1.31]$ & 0.5691 \\
\hline \multirow[t]{3}{*}{ Parsimonious model } & Normal weight & 1.0 & & 1.0 & \\
\hline & Overweight & $0.73[0.58-0.93]^{\mathrm{b}}$ & 0.0087 & $0.83[0.61-1.13]^{c}$ & 0.2383 \\
\hline & Obesity & $0.64[0.47-0.87]^{b}$ & 0.0043 & $0.98[0.71-1.36]^{\mathrm{C}}$ & 0.8914 \\
\hline
\end{tabular}

$\mathrm{HR}=$ Hazard Ratio, $\mathrm{Cl}=$ Confidence Interval, $\mathrm{BMI}=$ Body Mass Index.

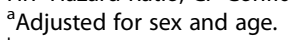

${ }^{\mathrm{b}}$ Adjusted for sex, age, stroke, smoking, re-infarction, left ventricular ejection fraction ( $<30 \%$ versus $\left.\geq 30 \%\right)$, any reperfusion treatment (coronary artery bypass surgery, percutaneous coronary intervention (PCl) or thrombolysis), beta-blockers (medication prior AMI), all four medications at discharge (antiplatelet agents, beta-blockers, ACEls/ARBs (Angiotensin-converting enzyme inhibitors/Angiotensin receptor blockers), statins).

${ }^{\mathrm{C}}$ Adjusted for sex, age, hyperlipidemia, re-infarction, any reperfusion treatment, statins (medication prior AMI), all four medications at discharge.

0.34-0.80; $\mathrm{p}=0.0027$ ) for overweight patients with diabetes who received stations prior AMI or all four EBMs at discharge. In contrast, no intake of statins had a beneficial effect on survival of both overweight and obese patients without diabetes, whereas receiving less than four medications at discharge was only beneficial for overweight patients without diabetes. In turn, obese patients without diabetes profited from receiving four medications at discharge.

\section{Discussion}

In this population-based study we could show that an elevated BMI in AMI patients had significant effects on long-term survival in AMI patients without diabetes. In

Table 3 Hazard ratios for mortality associated with elevated body mass index in patients with and without diabetes stratified by prescribed medications before and after myocardial infarction

\begin{tabular}{|c|c|c|c|c|c|}
\hline & & \multicolumn{2}{|c|}{ No diabetes $(n=2864)$} & \multicolumn{2}{|c|}{ Diabetes $(n=1190)$} \\
\hline & & $\mathrm{HR}[95 \% \mathrm{Cl}]$ & $\overline{p \text {-value }}$ & $\mathrm{HR}[95 \% \mathrm{Cl}]$ & $\overline{p \text {-value }}$ \\
\hline \multirow[t]{3}{*}{ Statins prior AMI } & Normal weight & 1.0 & & 1.0 & \\
\hline & Overweight & $0.81[0.44-1.52]^{a}$ & 0.5179 & $0.51[0.29-0.89]^{\mathrm{b}}$ & 0.0180 \\
\hline & Obesity & $0.59[0.26-1.35]^{\mathrm{a}}$ & 0.2115 & $0.82[0.46-1.47]^{\mathrm{b}}$ & 0.5102 \\
\hline \multirow[t]{3}{*}{ No statins prior AMl } & Normal weight & 1.0 & & 1.0 & \\
\hline & Overweight & $0.71[0.55-0.92]^{\mathrm{a}}$ & 0.0082 & $1.04[0.71-1.52]^{\mathrm{b}}$ & 0.8456 \\
\hline & Obesity & $0.66[0.47-0.92]^{a}$ & 0.0131 & $1.09[0.73-1.64]^{b}$ & 0.6697 \\
\hline \multirow[t]{3}{*}{ Four medications at discharge ${ }^{c}$} & Normal weight & 1.0 & & 1.0 & \\
\hline & Overweight & $0.76[0.56-1.03]^{\mathrm{e}}$ & 0.0805 & $0.52[0.34-0.80]^{f}$ & 0.0027 \\
\hline & Obesity & $0.56[0.37-0.86]^{\mathrm{e}}$ & 0.0072 & $0.82[0.54-1.26]^{f}$ & 0.3745 \\
\hline \multirow[t]{3}{*}{ Less than four medications at discharge ${ }^{d}$} & Normal weight & 1.0 & & 1.0 & \\
\hline & Overweight & $0.67[0.47-0.95]^{\mathrm{e}}$ & 0.0260 & $1.21[0.71-1.89]^{f}$ & 0.4095 \\
\hline & Obesity & $0.70[0.44-1.11]^{\mathrm{e}}$ & 0.1320 & $1.03[0.62-1.73]^{f}$ & 0.9062 \\
\hline
\end{tabular}

HR=Hazard Ratio, $\mathrm{Cl}=$ Confidence Interval, $\mathrm{AMI}=$ Acute Myocardial Infarction, $\mathrm{BMI}=$ Body Mass Index.

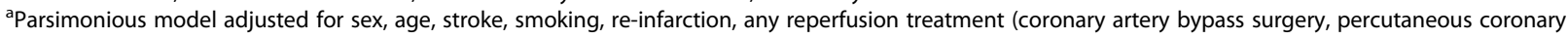
intervention ( $\mathrm{PCl}$ ) or thrombolysis), beta-blockers (medication prior $\mathrm{AMI}$ ), all four medications at discharge (antiplatelet agents, beta-blockers,

Angiotensin-converting enzyme inhibitors (ACEls)/Angiotensin receptor blockers (ARBs), statins), left ventricular ejection fraction (<30\% versus $\geq 30 \%)$.

${ }^{b}$ Parsimonious model adjusted for sex, age, hyperlipidemia, re-infarction, any reperfusion treatment, all four medications at discharge.

'Evidence-based medications (EBMs): Antiplatelet agents, beta-blockers, ACEls/ARBs, statins.

${ }^{\mathrm{d} E i t h e r}$ antiplatelet agents, beta-blockers, ACEIs/ARBs, statins or a combination of two or three of these medications.

eParsimonious model adjusted for sex, age, stroke, smoking, re-infarction, any reperfusion treatment, beta-blockers (medication prior AMI), left ventricular ejection fraction $(<30 \%$ versus $\geq 30 \%)$.

fParsimonious model adjusted for sex, age, hyperlipidemia, re-infarction, any reperfusion treatment, statins (medication prior AMI). 
contrast, no such association could be detected in patients with diabetes. Interestingly, being prescribed statins prior AMI or four EBMs at hospital-discharge, overweight patients with diabetes appeared to have a significant survival benefit. Furthermore, in patients without diabetes the detected survival benefit of overweight and obesity attenuated with increasing observation time.

In line with our findings, Adamopoulos et al. [18] reported the absence of an obesity paradox among patients with diabetes and chronic heart failure. However, differences in study design and the fact that only two BMI groups (obese versus non-obese) were compared resulted in limited comparability to our study. Contrary to our findings, two studies showed that normal weight patients with diabetes and preexisting cardiovascular events had the highest all-cause mortality rates compared to obese and overweight patients $[16,17]$. In addition, a study conducted in Japan compared 30-day survival rates following AMI of overweight (BMI $\geq$ $\left.25 \mathrm{~kg} / \mathrm{m}^{2}\right)$ and normal weight $\left(\mathrm{BMI}<25 \mathrm{~kg} / \mathrm{m}^{2}\right)$ patients with diabetes and found a significantly increased risk of dying among normal weight patients [24]. These contrasting results could derive from the very limited statistical power of the study as well as differences in study design. It has been shown that it can be misleading if BMI groups cover a wide range of values, since the association of BMI and mortality tends to follow a U- or J-shaped curve instead of increasing monotonically $[25,26]$.

Our findings in patients without diabetes are in line with results of previous studies on patients with AMI [3-8,24,27-29] as well as recent systematic reviews including studies on patients with cardiovascular disease [30-32]. However, only one study has analyzed AMI patients without diabetes separately [18].

Interestingly, stratified analyses revealed a significant survival benefit in overweight patients with diabetes who were being prescribed statins prior AMI as well as in overweight patients with diabetes who received all four EBMs at hospital discharge. One study concluded that a statin therapy in patients with diabetes and without previous CVD might have a beneficial effect on survival [33] and other studies have shown that prescribing all four EBMs at hospital discharge resulted in a significant reduction in long-term morbidity and mortality [22,34]. It has been also demonstrated that medications prescribed to treat hypertension (beta-blockers, ACEIs, ARBs) and elevated cholesterol levels (statins) exert pleiotropic effects on myocardial remodeling and mortality after a cardiovascular event such as AMI [34].

In our study, the survival benefit of overweight and obese patients without diabetes attenuated with increasing observation time. Therefore, previous studies focusing on short-term mortality might have overestimated the protective effect of overweight and obesity on survival after AMI. The paradoxically protective effect could only be valid over a short period of time [35] and the fact that it attenuated with increasing observation time in our analysis could be a result of patients' weight loss [17] or due to overweight and obese patients being more robust towards acute cardiovascular events.

Several factors could have caused the discrepancy in long-term survival in patients with and without diabetes: First, it can be hypothesized that an obesity paradox did not occur in patients with diabetes due to adverse effects of the disease or additional co-morbidities [36]. Combined with excess body weight they might be even more fatal. It has been shown that being overweight or obese does not exclude the possibility of being in a better cardiometabolic shape than normal weight patients [37]. A recent study demonstrated that normal weight patients with cardiometabolic dysfunction are at similar or even higher risk of cardiovascular morbidity and all-cause mortality in comparison with overweight and obese patients with cardiometabolic dysfunction [38]. However, in another study in patients with non-ST-segment elevation acute coronary syndrome only two components of the metabolic syndrome (low high-density lipoprotein and high triglycerides) were associated with higher 1year mortality when examined separately [39]. Furthermore, it has been suggested to differentiate between metabolically healthy and metabolically obese patients within the BMI groups to better understand the effects of metabolic syndrome [37]. The cardiometabolic burden of adiposity, certain components of the metabolic syndrome and additional comorbidities might therefore play an important role in the explanation of the obesity paradox $[37,38,40]$.

Second, we were not able to consider the time of diabetes diagnosis, the quality or stage of diabetes treatment as well as information on the treatment of overweight or obesity prior AMI. Previous studies revealed that the time of diabetes diagnosis might be relevant [41].

Third, additional comorbidities, such as cancer, changes in BMI as a result of weight gain or loss as well as adherence to prescribed medication after hospital discharge were not considered in our study. Recent findings indicate that BMI changes have an impact on long-term cardiovascular mortality [42].

Finally, there is evidence suggesting that the existence of an obesity paradox highly depends on the indices used to measure and classify normal weight, overweight and obesity $[16,43,44]$. Previous studies have shown that BMI combined with indices measuring the distribution of body-fat, such as waist-hip-ratio (WHR) or waist circumference (WC), offer more reliable results regarding mortality after cardiovascular events $[16,45,46]$. Especially in the context of CVDs, abdominal obesity is associated with a significantly increased mortality risk [47]. However, besides a higher adipose mass, overweight and obesity can be accompanied by an increase 
in lean mass, which might be, in turn, beneficial from a cardiometabolic perspective and could positively influence survival after cardiovascular events [8,37]. Moreover, abdominal obesity can also occur in normal weight people, which might increase their risk for cardiovascular events [37]. Using indices that better discriminate between fat and lean mass and that measure the distribution of body fat could help to shed light on this matter.

To our knowledge this is the first study investigating the association between BMI and long-term mortality in AMI patients that distinguished between patients with and without diabetes. This study has further strengths. First, important covariates such as medication prior and post AMI, inhospital treatment and complications as well as a selection of comorbidities, were included. Second, we were able to examine the impact of diabetes and BMI on mortality over a longer period of time than any other study in this field before. Third, excluding patients with a $\mathrm{BMI}<18.5 \mathrm{~kg} / \mathrm{m}^{2}$ ensured that patients with possible cachexia caused by other diseases, such as cancer, were not included in our sample. Fourth, data were collected in the framework of a population-based registry with consecutive enrollment. This approach ensured that all patients with an AMI within the study area, who reached the hospital alive and survived longer than 28 days, were included in the sample. Finally, in contrast to other studies, patients were considered to suffer from diabetes if their condition was confirmed by chart-review.

Potential limitations of this study should be taken into account. Changes in body weight during the long followup period could not be considered. Patients older than 74 years were not included in our study. Due to a considerable number of patients who died before reaching the hospital or in the course of 28 days we cannot exclude possible bias of our results. Information on other relevant conditions affecting survival after AMI, such as any malignant disease and impaired renal function were not collected in this study. The proportion of patients with type-1-diabetes only accounted for $2.1 \%$ of the study population with diabetes mellitus (data not shown). We therefore believe that the potential bias lies within tolerable limits. Finally, no data was available on the duration of therapy or treatment prior and post AMI as well as on the patients' compliance with taking prescribed medication before and after AMI had occurred.

\section{Conclusion}

In AMI patients without diabetes we detected a significant protective effect of overweight and obesity on all-cause mortality, which attenuated with increasing observation time while remaining statistically significant. However, in AMI patients with diabetes being overweight or obese did not result in a survival benefit. Surprisingly, a paradoxical association was found in overweight AMI patients with diabetes who had received statins prior AMI and who had been prescribed with four EBMs at hospital discharge.

In order to thoroughly investigate the association between BMI and all-cause mortality in patients with and without diabetes further studies are needed.

\section{Additional files}

Additional file 1: Further characteristics of patients with and without diabetes sub-divided into BMI groups.

Additional file 2: Hazard ratios of overweight and obese patients with and without diabetes over increasing observation time.

Additional file 3: Table supplementing Additional file 2: Hazard ratios for mortality associated with elevated body mass index in patients with and without diabetes over increasing observation time.

\section{Abbreviations}

ACEl: Angiotensin-converting enzyme inhibitor; AMl: Acute myocardial infarction; ANOVA: Analysis of variance; ARB: Angiotensin receptor blocker; BMI: Body mass index; Cl: Confidence interval; CVD: Cardiovascular disease; EBM: Evidence-based medication; HR: Hazard Ratio; IQR: Inter-quartile range; KORA: Cooperative Health Research in the Region of Augsburg; LVEF: Left ventricular ejection fraction; MI: Myocardial infarction; MONICA: Monitoring Trends and Determinants in Cardiovascular disease; NSTEMI: Non-ST-segment elevation myocardial infarction; PCl: Percutaneous coronary intervention; SD: Standard deviation; STEMI: ST-segment elevation myocardial infarction; VIF: Variance inflation factor; WC: Waist circumference; WHO: World Health Organization; WHR: Waist hip ratio.

\section{Competing interests}

The authors declare that they have no competing interests.

\section{Authors' contributions}

MGC and IK conceived the study. MGC performed the statistical analysis and drafted the manuscript. IK and UA supervised data analysis and manuscript drafting. CM, BK, WS, CM and AP contributed to the interpretation of data. $\mathrm{CM}, \mathrm{MH}, \mathrm{BK}$ and WS contributed to data acquisition. $\mathrm{CM}, \mathrm{AP}, \mathrm{MH}, \mathrm{BK}, \mathrm{WS}, \mathrm{IK}$ and UA critically revised the manuscript. All authors read and approved the final manuscript.

\section{Acknowledgements}

The KORA research platform and the MONICA Augsburg studies were initiated and financed by the Helmholtz Zentrum München, German Research Center for Environmental Health, which is funded by the German Federal Ministry of Education, Science, Research and Technology and by the State of Bavaria. Since the year 2000, the collection of MI data has been co-financed by the German Federal Ministry of Health to provide population-based MI morbidity data for the official German Health Report (see www.gbe-bund.de). Steering partners of the MONICA/KORA Infarction Registry, Augsburg, include the KORA research platform, Helmholtz Zentrum München and the Department of Internal Medicine I, Cardiology, Central Hospital of Augsburg. We thank all members of the Helmholtz Zentrum München, Institute of Epidemiology II and the field staff in Augsburg who were involved in the planning and conduct of the study. We wish to thank the local health departments, the office-based physicians and the clinicians of the hospitals within the study area for their support. Finally, we express our appreciation to all study participants.

\section{Author details}

${ }^{1}$ Central Hospital of Augsburg, MONICA/KORA Myocardial Infarction Registry, Stenglinstr. 2, 86156 Augsburg, Germany. ${ }^{2}$ Helmholtz Zentrum München, German Research Center for Environmental Health $(\mathrm{GmbH})$, Institute of Epidemiology II, Ingolstädter Landstr. 1, 85764 Neuherberg, Germany. ${ }^{3}$ Central Hospital of Augsburg, Department of Internal Medicine I-Cardiology, Stenglinstr. 2, 86156 Augsburg, Germany. ${ }^{4}$ Hospital of Nördlingen, Department of Internal Medicine/Cardiology, Stoffelsberg 4, 86720 Nördlingen, Germany. 
Received: 27 November 2014 Accepted: 4 February 2015 Published online: 18 February 2015

\section{References}

1. Berrington De Gonzalez A, Hartge P, Cerhan JR, Flint AJ, Hannan L, Maclnnis $\mathrm{RJ}$, et al. Body-mass index and mortality among 1.46 million white adults. N Engl J Med. 2010;363(23):2211-9.

2. Gelber RP, Gaziano JM, Orav EJ, Manson JE, Buring JE, Kurth T. Measures of obesity and cardiovascular risk among men and women. J Am Coll Cardiol. 2008;52(8):605-15.

3. Bucholz EM, Rathore SS, Reid KJ, Jones PG, Chan PS, Rich MW, et al. Body mass index and mortality in acute myocardial infarction patients. Am J Med. 2012;125(8):796-803.

4. Buettner HJ, Mueller C, Gick M, Ferenc M, Allgeier J, Comberg T, et al. The impact of obesity on mortality in UA/non-ST-segment elevation myocardial infarction. Eur Heart J. 2007;28(14):1694-701.

5. Wienbergen $H$, Gitt AK, Juenger $C$, Schiele $R$, Heer $T$, Towae $F$, et al. group MPs: impact of the body mass index on occurrence and outcome of acute ST-elevation myocardial infarction. Clin Res Cardiol. 2008;97(2):83-8.

6. Timoteo AT, Ramos R, Toste A, Oliveira JA, Ferreira ML, Ferreira RC. Impact of body mass index in the results after primary angioplasty in patients with ST segment elevation acute myocardial infarction. Acute Card Care. 2011;13(3):123-8.

7. Kragelund C, Hassager C, Hildebrandt P, Torp-Pedersen C, Kober L, group Ts. Impact of obesity on long-term prognosis following acute myocardial infarction. Int J Cardiol. 2005;98(1):123-31.

8. O'Brien EC, Fosbol EL, Peng SA, Alexander KP, Roe MT, Peterson ED. Association of body mass index and long-term outcomes in older patients with non-ST-segment-elevation myocardial infarction: results from the CRUSADE Registry. Circ Cardiovasc Qual Outcomes. 2014;7(1):102-9.

9. Gregg EW, Gu Q, Cheng YJ, Narayan KM, Cowie CC. Mortality trends in men and women with diabetes, 1971 to 2000. Ann Intern Med. 2007;147(3):149-55.

10. Preis SR, Hwang SJ, Coady S, Pencina MJ, D'Agostino Sr RB, Savage PJ, et al. Trends in all-cause and cardiovascular disease mortality among women and men with and without diabetes mellitus in the Framingham Heart Study, 1950 to 2005. Circulation. 2009;119(13):1728-35.

11. Haffner SM, Lehto S, Ronnemaa T, Pyorala K, Laakso M. Mortality from coronary heart disease in subjects with type 2 diabetes and in nondiabetic subjects with and without prior myocardial infarction. N Engl J Med. 1998;339(4):229-34.

12. Buse JB, Ginsberg HN, Bakris GL, Clark NG, Costa F, Eckel R, et al. Primary prevention of cardiovascular diseases in people with diabetes mellitus: a scientific statement from the American Heart Association and the American Diabetes Association. Circulation. 2007;115(1):114-26.

13. Mukamal K, Nesto RW, Cohen MC, Muller JE, Maclure M, Sherwood JB, et al. Impact of diabetes on long-term survival after acute myocardial infarction: comparability of risk with prior myocardial infarction. Diabetes Care. 2001;24(8):1422-7.

14. Mathew $V$, Holmes DR. Outcomes in diabetics undergoing revascularization: the long and the short of it. J Am Coll Cardiol. 2002;40(3):424-7.

15. lijima R, Ndrepepa G, Mehilli J, Markwardt C, Bruskina O, Pache J, et al. Impact of diabetes mellitus on long-term outcomes in the drug-eluting stent era. Am Heart J. 2007;154(4):688-93.

16. Dallongeville J, Bhatt DL, Steg PH, Ravaud P, Wilson PW, Eagle KA, et al. Relation between body mass index, waist circumference, and cardiovascular outcomes in 19,579 diabetic patients with established vascular disease: the REACH Registry. Eur J Prev Cardiol. 2012;19(2):241-9.

17. Doehner W, Erdmann E, Cairns R, Clark AL, Dormandy JA, Ferrannini E, et al. Inverse relation of body weight and weight change with mortality and morbidity in patients with type 2 diabetes and cardiovascular co-morbidity: an analysis of the PROactive study population. Int J Cardiol. 2012;162(1):20-6.

18. Adamopoulos C, Meyer P, Desai RV, Karatzidou K, Ovalle F, White M, et al. Absence of obesity paradox in patients with chronic heart failure and diabetes mellitus: a propensity-matched study. Eur J Heart Fail. 2011;13(2):200-6.

19. Kuch B, Heier M, Von Scheidt W, Kling B, Hoermann A, Meisinger C. 20-year trends in clinical characteristics, therapy and short-term prognosis in acute myocardial infarction according to presenting electrocardiogram: the MONICA/KORA AMI Registry (1985-2004). J Intern Med. 2008;264(3):254-64.

20. Meisinger C, Hormann A, Heier M, Kuch B, Lowel H. Admission blood glucose and adverse outcomes in non-diabetic patients with myocardial infarction in the reperfusion era. Int J Cardiol. 2006;113(2):229-35.
21. Obesity: preventing and managing the global epidemic. Report of a $\mathrm{WHO}$ consultation. World Health Organization technical report series 2000, 894:i-xii, 1-253.

22. Amann U, Kirchberger I, Heier M, Goluke H, Von Scheidt W, Kuch B, et al. Long-term survival in patients with different combinations of evidencebased medications after incident acute myocardial infarction: results from the MONICA/KORA Myocardial Infarction Registry. Clin Res Cardiol. 2014;103(8):655-64.

23. When can you safely ignore multicollinearity? [http://www.statisticalhorizons. com/multicollinearity]

24. Ikeda N, Nakajima R, Utsunomiya M, Hori M, Itaya H, Makino K, et al. Higher body mass index at the time of acute myocardial infarction is associated with a favorable long-term prognosis (8-year follow-up). Heart Vessels. 2011;26(5):495-501.

25. Logue J, Walker JJ, Leese G, Lindsay R, McKnight J, Morris A, et al. Association between BMI measured within a year after diagnosis of type 2 diabetes and mortality. Diabetes Care. 2013;36(4):887-93.

26. Prospective Studies C, Whitlock G, Lewington S, Sherliker P, Clarke R, Emberson J, et al. Body-mass index and cause-specific mortality in 900000 adults: collaborative analyses of 57 prospective studies. Lancet. 2009;373(9669):1083-96.

27. Dhoot J, Tariq S, Erande A, Amin A, Patel P, Malik S. Effect of morbid obesity on in-hospital mortality and coronary revascularization outcomes after acute myocardial infarction in the United States. Am J Cardiol. 2013;111(8):1104-10.

28. Kang WY, Jeong MH, Ahn YK, Kim JH, Chae SC, Kim YJ, et al. Obesity paradox in Korean patients undergoing primary percutaneous coronary intervention in ST-segment elevation myocardial infarction. J Cardiol. 2010;55(1):84-91.

29. Mehta L, Devlin W, McCullough PA, O'Neill WW, Skelding KA, Stone GW, et al. Impact of body mass index on outcomes after percutaneous coronary intervention in patients with acute myocardial infarction. Am J Cardiol. 2007;99(7):906-10.

30. Hainer V, Aldhoon-Hainerova I. Obesity paradox does exist. Diabetes Care. 2013;36 Suppl 2:S276-81.

31. Ghoorah K, Campbell P, Kent A, Maznyczka A, Kunadian V. Obesity and cardiovascular outcomes: a review. Eur Heart J Acute Cardiovasc Care. 2014. [Epub ahead of print]. doi:10.1177/2048872614523349.

32. McAuley PA, Blair SN. Obesity paradoxes. J Sports Sci. 2011;29(8):773-82.

33. Wienbergen $H$, Senges J, Gitt AK. Should we prescribe statin and aspirin for every diabetic patient? Is it time for a polypill? Diabetes Care. 2008;31 Suppl 2:S222-5.

34. Porter KE, Turner NA. Cardiac fibroblasts: at the heart of myocardial remodeling. Pharmacol Ther. 2009;123(2):255-78.

35. Oreopoulos A, Padwal R, Norris CM, Mullen JC, Pretorius V, Kalantar-Zadeh K. Effect of obesity on short- and long-term mortality postcoronary revascularization: a meta-analysis. Obesity. 2008;16(2):442-50.

36. Beckman JA, Creager MA, Libby P. Diabetes and atherosclerosis: epidemiology, pathophysiology, and management. JAMA. 2002;287 (19):2570-81.

37. Mourmoura E, Chate V, Couturier K, Laillet B, Vial G, Rigaudiere JP, et al. Body adiposity dictates different mechanisms of increased coronary reactivity related to improved in vivo cardiac function. Cardiovasc Diabetol. 2014;13:54.

38. Van Der Leeuw J, Van Der Graaf Y, Nathoe HM, De Borst GJ, Kappelle LJ, Visseren $\mathrm{FL}$, et al. The separate and combined effects of adiposity and cardiometabolic dysfunction on the risk of recurrent cardiovascular events and mortality in patients with manifest vascular disease. Heart. 2014;100(18):1421-9.

39. Mehta RH, Westerhout CM, Zheng Y, Giugliano RP, Huber K, Prabhakaran D, et al. Association of metabolic syndrome and its individual components with outcomes among patients with high-risk non-ST-segment elevation acute coronary syndromes. Am Heart J. 2014;168(2):182-8. e181.

40. Herrmann J, Gersh BJ, Goldfinger JZ, Witzenbichler B, Guagliumi G, Dudek $D$, et al. Body mass index and acute and long-term outcomes after acute myocardial infarction (from the Harmonizing Outcomes with Revascularization and Stents in Acute Myocardial Infarction Trial). Am J Cardiol. 2014;114(1):9-16.

41. Carnethon MR, De Chavez PJ, Biggs ML, Lewis CE, Pankow JS, Bertoni AG, et al. Association of weight status with mortality in adults with incident diabetes. JAMA. 2012;308(6):581-90.

42. Bodegard J, Sundstrom J, Svennblad B, Ostgren CJ, Nilsson PM, Johansson G. Changes in body mass index following newly diagnosed type 2 diabetes 
and risk of cardiovascular mortality: a cohort study of 8486 primary-care patients. Diabetes Metab. 2013;39(4):306-13.

43. Chrysant SG, Chrysant GS. New insights into the true nature of the obesity paradox and the lower cardiovascular risk. J Am Soc Hypertens. 2013;7(1):85-94.

44. De Schutter A, Lavie CJ, Kachur S, Patel DA, Milani RV. Body composition and mortality in a large cohort with preserved ejection fraction: untangling the obesity paradox. Mayo Clin Proc. 2014;89(8):1072-9.

45. Coutinho T, Goel K, Correa De Sa D, Kragelund C, Kanaya AM, Zeller M, et al. Central obesity and survival in subjects with coronary artery disease: a systematic review of the literature and collaborative analysis with individual subject data. J Am Coll Cardiol. 2011;57(19):1877-86.

46. Clark AL, Chyu J, Horwich TB. The obesity paradox in men versus women with systolic heart failure. Am J Cardiol. 2012;110(1):77-82.

47. Fontes-Carvalho R, Fontes-Oliveira M, Sampaio F, Mancio J, Bettencourt N, Teixeira $M$, et al. Influence of epicardial and visceral fat on left ventricular diastolic and systolic functions in patients after myocardial infarction. Am J Cardiol. 2014;114(11):1663-9.

\section{Submit your next manuscript to BioMed Central and take full advantage of:}

- Convenient online submission

- Thorough peer review

- No space constraints or color figure charges

- Immediate publication on acceptance

- Inclusion in PubMed, CAS, Scopus and Google Scholar

- Research which is freely available for redistribution 